\title{
Out-of-Home Care for Infants and Toddlers: A Call for Cultural and Linguistic Continuity
}

\section{Janet Gonzalez-Mena}

Napa Valley College

Judith K. Bernhard

Ryerson University

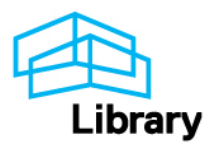




\title{
Out-of-Home Care of Infants and Toddlers: A Call for Culfural Linguistic Continuity
}

\author{
by Janet Gonzalez-Mena and Judith K. Bernhard
}

\begin{abstract}
Angel's big dark eyes stare at her caregiver Kimberly. Angel's brown face is a contrast to the paleness of Kimberly's arm where she lies nestled. Kimberly speaks to Angel using soft tones. Angel turns away looking uncomfortable. Is she noticing that Kimberly's way of holding her is different from her mother's? Kimberly's voice and body language are different too.
\end{abstract}

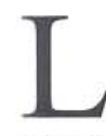

et's peek inside Angel's head and see what is going on. Of course she is too young to talk, but pretend we can understand what she is thinking. She has three things on her mind. One is the way that this person looks, sounds, and smells — nothing like her mother. The second is the way this person is looking at her. In Angel's culture nobody focuses in on a baby's face like that. Angel isn't used to being talked to directly. It's very strange. She's used to plenty of talking - but it's louder and usually aimed at somebody else. Third and most of all, she's missing the many little body messages that her mother continually sends her. She and her mother communicate all the time, just not in this unfamiliar way.

The purpose of this article is to help you think about what can happen when caregivers of one culture care for babies of another. We're not out to explain research (which is scanty). We can't tell you that a certain kind of mismatch in infancy will have a specific effect 20 years later. Nobody has that kind of knowledge. What the two of us do know from our collective experience is that mismatches occur and they can cause problems. One of the worst problems happens when children reject their home culture and language, and become disconnected from their families.

Most of us concerned with infant-toddler care like to think early cross-cultural experiences have a positive effect. After all, many babies today are in out-of-home care with caregivers who aren't of their culture. We would like to assume this is a good situation. For some babies it is. Most of us have known babies who have had cross-cultural experiences and benefited. We tell ourselves that a cross-cultural or multicultural experience makes babies more open to diversity. It's hard to acknowledge that for some babies such experiences may hamper formation of a self-identity. Nevertheless, without a firm sense of who they are, many children grow up marginalized, feeling like they don't belong anywhere. Commonly, many minority children take on the mainstream culture and language and reject their own.

\section{Cultural differences can be major changes for a baby.}

Most babies adapt when they experience just a few differences in caregiving styles. Even within a single culture there are differences in style. But what if babies are faced with many major changes? Imagine a baby's reaction if she has never slept alone and suddenly finds herself in a crib off in a dark room? A baby who has spent all her waking hours being held might feel scared if put on the floor by herself to play.
What about a baby who is put into diapers when he has never worn them before? Some babies are conditioned from birth to use a potty (with help, of course). The baby in diapers for the first time may feel abandoned when no one puts him on the potty. What about a toddler who is used to having a lot of help and reminders about using the potty? If she finds herself in a situation where the caregivers assume she'll take care of her own toileting, she may wet her pants and feel badly about it. Think of a toddler in a situation where the caregiver expects him to feed himself finger food, but at home he is taught never to touch his food. He'll have to make a decision about what to do in the face of this serious contradiction.

Very likely, the caregivers in the above examples have an overall goal to help children develop into independent individuals. The caregivers may, perhaps, consider independence a universal priority. It isn't. In some cultures independence is considered a problem not a blessing. Independence training is avoided because it gets in the way of relationships.

Consider a family whose foremost goal is connectedness. Their child-rearing practices are designed to create closeness and reliance on one another rather than self-sufficiency. Members of this family may try to weaken what they consider a natural drive toward independence; they worry that their child will become too independent and will grow apart from them. They're not interested in encouraging self-sufficiency, because they know that it will come anyway, whether you train children for it or not. When independence does finally come, they want to be sure those family ties they've been developing are strong enough to last a lifetime.

\section{Caregiving practices matter.}

Parental child-rearing practices are designed to prepare children for adulthood in the family's culture. The first objective of the caregiver must be to find out the families' practices and how they relate to their goals. Naturally, the task is easier when the caregivers are of the same culture as the families. Cultural consistency makes it more likely that children will get a good grounding in the skills important to their people. Of 


\section{F $\quad \mathrm{O} \quad \mathrm{C} \quad \mathrm{U} \quad \mathrm{S}$ ANTI-BIAS}

course, it may be impossible to match all babies with caregivers of their own cultures. In those cases it is imperative that caregivers be respectful of diversity and sensitive to cultural differences. Only then can they respond appropriately.

Some caregivers may ask, "How can I possibly learn about all the cultures represented by the babies I care for?" Granted, it can be an enormous task, but not an impossible one as long as caregivers are willing learners. Just as you get to know each individual baby and his or her needs, so you can get to know families and understand their needs and cultural priorities.

To succeed, it takes a small group size, a good ratio, and "continuity of care," meaning a caregiver remains with the same babies over a long enough period of time to really get to know the families. Three years is optimum. Personal qualities of the caregiver help too - such as an open mind and a willingness to understand that what you think is normal or right may, in fact, not be. Cribs, diapers and finger food relate to standard practices, but none of those standard practices are universal. Families around the world rear babies without cribs, diapers and finger foods. Some of those families are now in our programs.

Infants and toddlers are just beginning to be part of their own culture and language group. We've already said that whether they eventually fit in and feel good about their culture and language depends to some extent on their early experiences. We haven't said yet though, that dangers lie in unspoken messages by the members of the dominant culture and the media about the perceived superiority of the dominant culture. If children learn to look at their home culture as inferior, they may take in a negative view of themselves and their families.

\section{Infants and toddlers become} members of their culture.

Caregivers must become aware that there is nothing in a young child's day that comes separate from its cultural context.

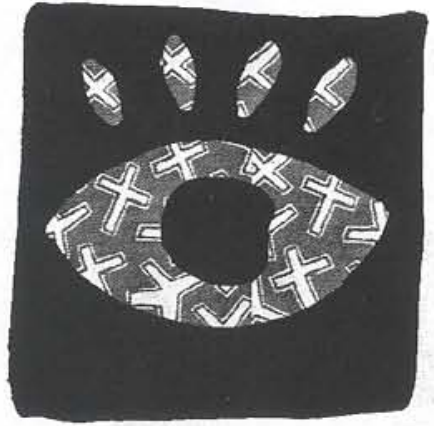

dominant culture and language. We're not suggesting that anyone be forever isolated from the dominant culture and language. Our vision is a pluralistic society built on the principles of equity and social justice. We think education for such a society starts in infancy as children and families are valued for who they are.

Janet Gonzalez-Mena is on the faculty of Child and Family Studies at Napa Valley College in California. She has published several books and articles about child care.

Culture is not directly taught, but grows out of the interactions between caregivers and children. Babies are born with the need to attach to and become involved with other people and their surroundings; they naturally observe and attend. Sensitive adults respond by constantly adjusting their behaviours and structuring the environment in ways that provide support for development and learning. Culture is the medium in which all this occurs and in child care, whether that medium matches or is in conflict with the home culture is very important. Steps should be taken to create an optimum match for infants and toddlers, especially those at risk of losing or rejecting their home culture.

Language is a key part of the picture too. Culture and language are vitally tied together. Furthermore, infants' and toddlers' overall language skill depends, to some extent at least, on their continuing to develop in their home language. If caregivers don't speak the home language, they can at least encourage those who do to use it. It's important for families to understand the benefits of maintaining their mother tongue and culture. If caregivers learn even a few words, their effort gives a positive message to children and families.

\section{Bilingualism/biculturalism is ultimate goal.}

Immigrant and minority children who are firmly rooted in their home culture and language will eventually be ready to become empowered in the
Judith K. Bernhard is on the faculty of the School of Early Childhood Education at Ryerson Polytechnic University where she teaches courses on child development. Her focus is on pluralistic models that honour the role of culture in determining optimal a child development book to be published in 2002.

\section{Suggested Further Reading}

Bernhard, J. K. (1995). "The Changing Field of Child Development: Cultural Diversity and the Professional Training of Early Childhood Educators." Canadian Journal of Education, 20 (4), 415-436.

Bernhard, J. K., Lefebvre, M. L., Murphy Kilbride, K., Chud, G., Lange, R.(1995). Paths to Equity: Early Childhood Education. Toronto: York Lanes Press. Caudill, W., \& Plath, D. W. (1966). "Who Sleeps by Whom? Parent-child Involvement in Urban Japanese Families." Psychiatry, 29, 344-366.

Dotsch, J. (1992). Newcomer Preschool Children: Their Cultural and Linguistic Adaptation to Childcare Settings. Unpublished manuscript. Toronto: Ontario Welcome House.

Drolet, C. (1994). "S'adapter à la diversité : faits saillants d'une enquête sur la diversité ethnoculturelle dans les services de garde en garderie et en milieu familial et dans les agences de la région de Montréal." Petit à petit, 12 (6), 8-10.

Gonzalez-Mena, J. (1997). Multicultural Issues in Child Care. Mountain View, California: Mayfield Publishing. Hall, N.S. \& Rhomberg, V. (1995). The Affective Curriculum. Toronto: Nelson.

LaGrange, A., Clark, D., Munroe, E. (1994). Culturally Sensitive Child Care: The Alberta Study. Edmonton: Alberta Association for Young Children.

Lally, J. R. (1996). "The Impact of Child Care Policies and Practices on Infant/Toddler Identity Formation." Young Children, 51 (1), 58-67.

Lefebvre, M.L. (1990). "Un enfant, quatre milieux : l'intégration des enfants immigrants dans les Services de Garde en Milieu Scolaire." Grandir avec toi. Actes du 4 è congrès sur les services de garde en milieu scolaire, Montréal : SGEMSQ.

Mangione, P. (Ed.) (1995). Infant/Toddler Caregiving: A Far West Laboratory and California Department of Education.

Phillips, C. B., \& Cooper, R. M. (1992). "Cultural Dimensions of Feeding Relationships." Zero to Three, 12(5), 10-13.

Shwalb, D. W., Shwalb, B. J. \& Shoji, J. (1996). "Japanese Mothers' Ideas About Infants and Temperament." In S. Harkness \& C. Super (Eds.) Parental Cultural Belief Systems: Their Origins, Expressions, and Consequences. NY: Guilford Press, 169-191. caregiving practices. Judith and Janet are co-authoring Cultural, Linguistic and Racial Diversity in Canadian Guide to Culturally Sensitive Care. Sacramento, CA: 